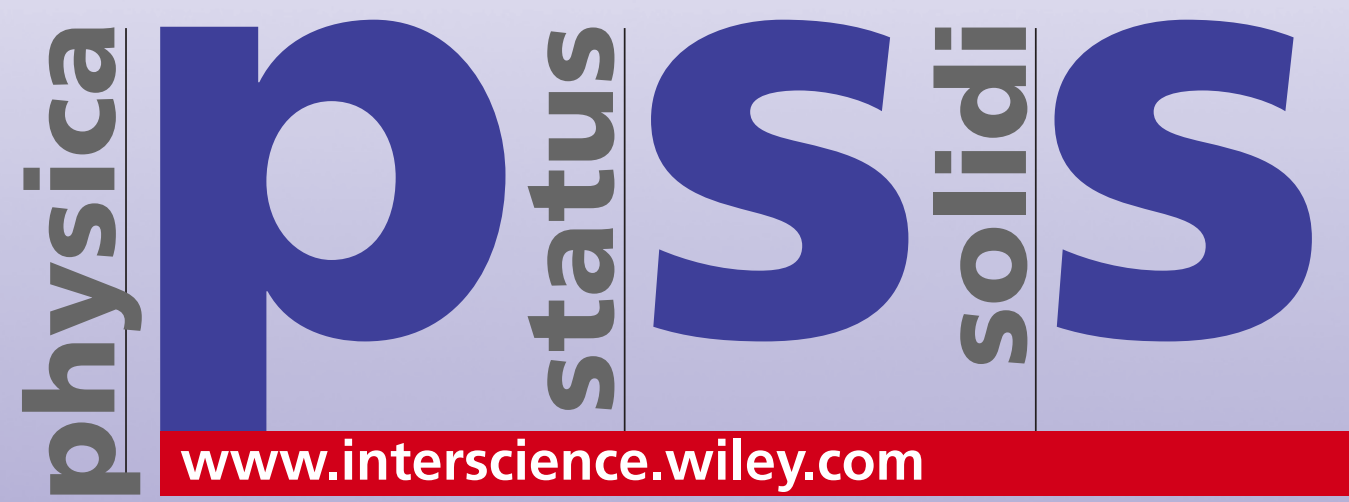

\title{
reprints
}

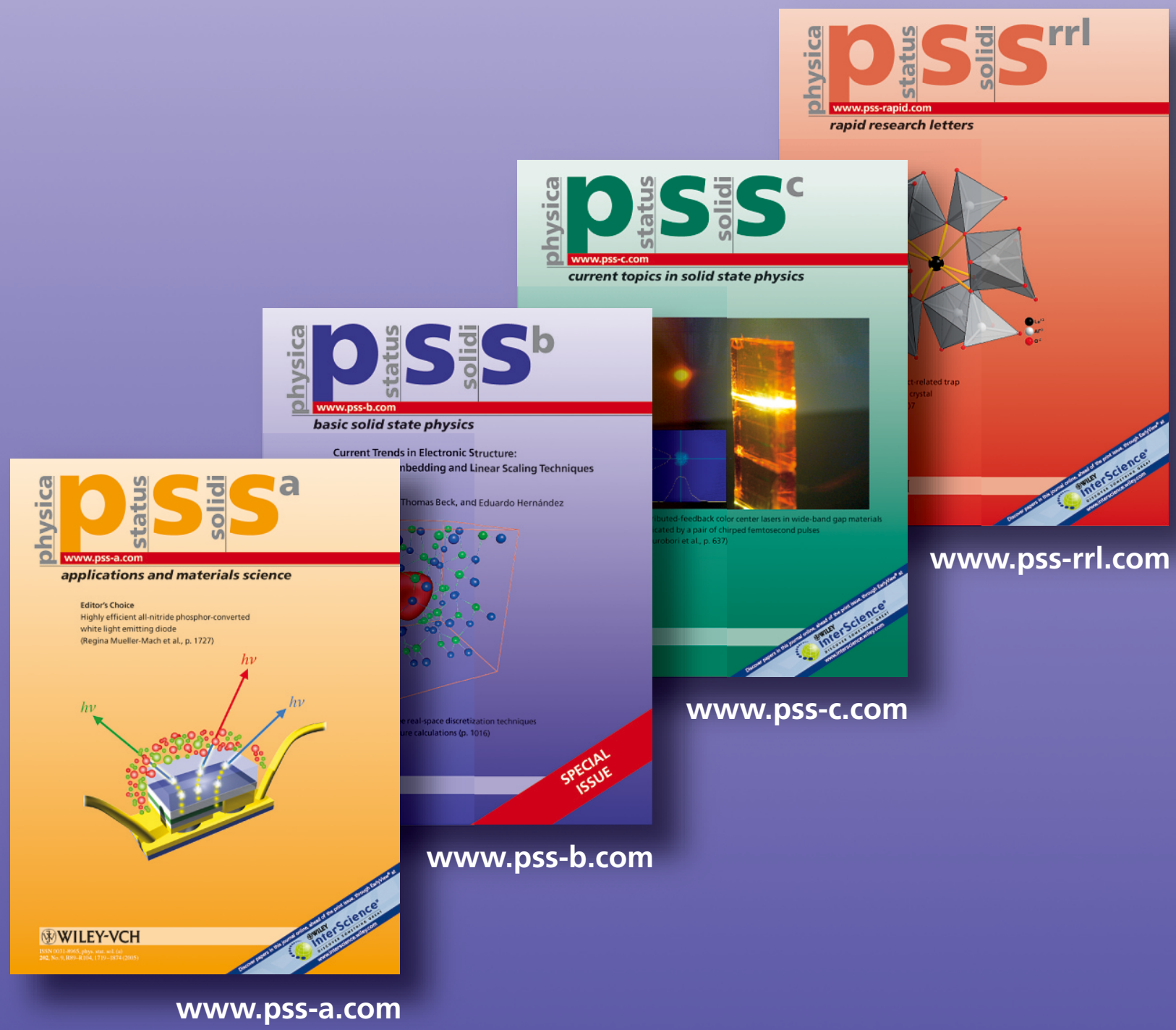




\title{
Phase structure and crystallization of the bulk glassy FeCoZrWB alloys
}

\author{
Katarzyna Pawlik ${ }^{*, 1}$, Jozef Bednarcik ${ }^{2}$, Piotr Pawlik ${ }^{1}$, Jerzy J. Wysłocki ${ }^{1}$, Waldemar Kaszuwara ${ }^{3}$, \\ Bartosz Michalski ${ }^{3}$, and Piotr Gębara ${ }^{1}$ \\ ${ }^{1}$ Institute of Physics, Częstochowa University of Technology, Al. Armii Krajowej 19, 42-200 Częstochowa, Poland \\ ${ }^{2}$ HASYLAB at DESY, Notkestr. 85, 22607 Hamburg, Germany \\ ${ }^{3}$ Faculty of Materials Science and Engineering, Warsaw University of Technology, ul. Wołoska, 141, 02-507 Warsaw, Poland
}

Received 23 September 2009, revised 13 November 2009, accepted 3 December 2009

Published online 19 April 2010

Keywords Fe-alloys, XRD, structure, crystallization, DSC

* Corresponding author: e-mail pawlik@wip.pcz.pl, Phone: +48 343250 795, Fax: +48 343250795

In the present work, the high-energy X-ray diffraction (XRD) measurements performed using monochromatic synchrotron radiation of $112 \mathrm{keV}(\lambda=0.110696 \AA$ ), were utilized to compare a phase constitution of melt-spun ribbon and suction-cast rods of $\mathrm{Fe}_{61} \mathrm{Co}_{10+\mathrm{x}} \mathrm{Zr}_{5} \mathrm{~W}_{4-\mathrm{x}} \mathrm{B}_{20}$ alloys (where $\mathrm{x}=0,2,3$ at.\%). For bulk amorphous samples of the investigated alloys DSC studies allowed to determine the activation energies of crystal growth and differences in crystallization kinetics at constant heating rates.
1 Introduction It was shown in previous works [1, 2], that the increase of $\mathrm{W}$ contents in $\mathrm{Fe}_{61} \mathrm{Co}_{10+\mathrm{x}} \mathrm{Zr}_{5} \mathrm{~W}_{4-\mathrm{x}} \mathrm{B}_{20}$ alloys (where $\mathrm{x}=0,2,3$ at.\%), results in significant rise of their glass forming abilities (GFA). For the $\mathrm{x}=0$ alloy it was possible to process up to $2 \mathrm{~mm}$ diameter amorphous rods, while for the $\mathrm{x}=3$ alloy, only $0.5 \mathrm{~mm}$ diameter glassy rods were produced by suction-casting technique. However, potential low fraction of crystalline phase present in the rod samples was impossible to detect by conventional $\mathrm{XRD}$ equipment, therefore the synchrotron radiation is, due to its advantages, more preferred technique of studying the structure of bulk glassy alloys.

Differential scanning calorimetry (DSC) is an important tool for investigation of the crystallization kinetic in glassy alloys. In many publications Kissinger [3] or Ozawa [4] relations, were utilized to calculate the activation energy of crystal growth from DSC plots measured at various heating rates $\alpha$. According to first model the activation energy is related to a slope of $\ln \left(\mathrm{T}_{\mathrm{p}}{ }^{2} / \alpha\right)$ vs. $1 / \mathrm{T}_{\mathrm{p}}$, along the equation:

$$
\ln \left(\frac{T_{p}^{2}}{\alpha}\right)=\frac{E_{c}}{R T_{p}}+\text { const. }
$$

where $T_{p}$-temperatures related to maximum of crystallization peaks in DSC curves measured at various heating rates $\alpha$.

Similarly, in Ozawa model the slope of $\ln \alpha$ vs. 1/T (where $\mathrm{T}$ is the temperature, at which crystal volume fraction reaches specific value), allows to determine the activation energy $E_{c}$. However, the analysis of crystallization kinetics in amorphous alloys using both models gives the results not taking into account the specific of nucleation and growth of the crystalline phase. Also Johnson-Mehl-Avrani equation is frequently used to study the crystallization kinetics of amorphous materials [5-7]. However, the model was derived for isothermal crystallization processes [8], even though the obtained activation energies reach reasonable values. Therefore in the present work Matusita model [9] was used to investigate crystallization processes in the investigated alloys. In this approach, the reversed proportion between the number of crystallites in the unit volume $\mathrm{N}$ and the heating rate $\alpha$ is assumed. Furthermore, the influence of various ways of crystal growth during constant heating rate is taken into account. A volume fraction of crystalline phase $\mathrm{x}$ at the temperature $\mathrm{T}$, precipitating during constant heating rate is calculated from the crystallization peak on DSC curve and is defined as $x=A_{T} / A$, where $A$ - is the area under the whole crystallization peak and $A_{T}$ 
- a fraction of this area measured between the crystallization temperature $T_{x}$ and a given temperature $T$ higher than $\mathrm{T}_{\mathrm{x}}$.

Relation between $\mathrm{x}$ and the heating rate $\alpha$ is expressed as follows:

$$
\ln [-\ln (1-x)]=-n \ln \alpha-1.052 m \frac{E_{c}}{R T}+\text { const. }
$$

where $\mathrm{m}=1,2$ or 3 for one-, two- or three-dimensional growth of crystal particles, while $\mathrm{n}$ is a parameter dependent on the fraction of crystalline phase present in the sample subjected to heating at constant heating rate. For fully amorphous samples $n=m+1$, while for partly crystalline alloys $n=m[9]$.

The aim of present work was to determine the influence of $\mathrm{W}$ contents on crystallization kinetics in amorphous $\mathrm{Fe}_{61} \mathrm{Co}_{10+\mathrm{x}} \mathrm{Zr}_{5} \mathrm{~W}_{4-\mathrm{x}} \mathrm{B}_{20}$ alloys (where $\mathrm{x}=0,2,3$ at.\%).

2 Samples preparation and the experimental methods Samples of $\mathrm{Fe}_{61} \mathrm{Co}_{10+\mathrm{x}} \mathrm{Zr}_{5} \mathrm{~W}_{4-\mathrm{x}} \mathrm{B}_{20}$ alloys ( $\mathrm{x}=0$, 2, 3 ) were produced by arc-melting under an Ar atmosphere, the high purity elements of $\mathrm{Fe}, \mathrm{Co}, \mathrm{W}$ and $\mathrm{Zr}$ with addition of the Fe-B pre-alloy of known, chemically analyzed composition. From the alloy precursors, the ribbon samples of various thicknesses $t_{r}$ were produced by controlled atmosphere melt-spinning method. The rod samples of various diameters were produced by suction-casting of the melt into a split copper die, by the argon pressure difference between two chambers integrated with the arc-melting unit. The high-energy X-ray diffraction (XRD) measurements performed using monochromatic synchrotron radiation of $112 \mathrm{keV}(\lambda=0.110696 \AA$ \&́) at undulator beamline PETRA 2 of synchrotron facility DESY/HASYLAB (Hamburg, Germany), were utilized to compare a phase constitution of melt-spun ribbon and suction-cast rods.

The DSC studies were carried out on amorphous $1 \mathrm{~mm}$ diameter rods of the $\mathrm{x}=0$ and $\mathrm{x}=2$ alloys and $0.5 \mathrm{~mm}$ rods of the $x=3$ alloy. Measurements were performed under the $\mathrm{Ar}$ atmosphere with the heating rates 10,25 and $40 \mathrm{~K} / \mathrm{min}$.

\section{Results and discussion}

3.1 X-ray diffraction of the synchrotron radiation X-ray diffraction using monochromatic beam of synchrotron radiation carried out on ribbon samples of the $\mathrm{Fe}_{61} \mathrm{Co}_{10} \mathrm{Zr}_{5} \mathrm{~W}_{4} \mathrm{~B}_{20}$ alloy are shown in Fig. 1. For ribbon samples of various thicknesses, diffraction peaks related to crystalline phase were not observed, suggesting their fully glassy structure. Similar diffractions were measured for the ribbons of the other two alloy compositions. As we have previously demonstrated [1] using conventional X-ray diffractometry, the glass forming abilities of the alloy depend on the $\mathrm{W}$ contents, so that the largest diameters of fully glassy rods were produced for the $\mathrm{x}=0$ alloy. Therefore, the XRD using synchrotron radiation were performed on $1.5,1$ and $0.5 \mathrm{~mm}$ rod samples respectively for $\mathrm{x}=0, \mathrm{x}=2$ and $\mathrm{x}=3$ alloys, in order to identify the traces of some crystalline precipitates in the bulk glassy rods (Fig. 2a). In case of 0.5 $\mathrm{mm}$ dia. rods of the $\mathrm{Fe}_{61} \mathrm{Co}_{13} \mathrm{Zr}_{5} \mathrm{~W}_{1} \mathrm{~B}_{20}$ alloy no diffraction peaks attributed to any crystalline phase, were observed.

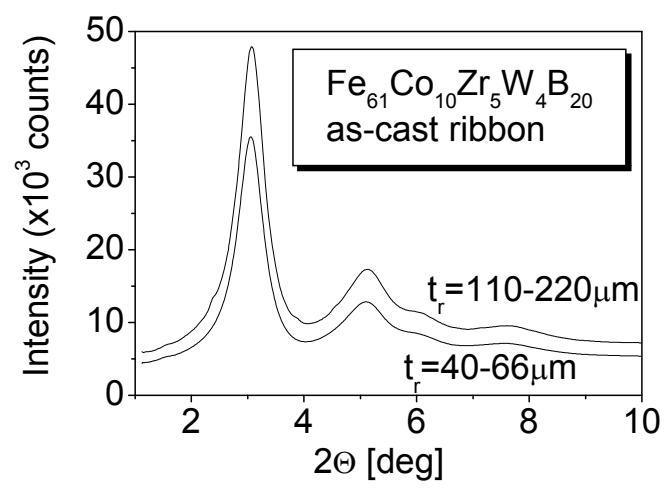

Figure $1 \mathrm{XRD}$ scans for the $\mathrm{Fe}_{61} \mathrm{Co}_{10} \mathrm{Zr}_{5} \mathrm{~W}_{4} \mathrm{~B}_{20}$ alloy as-cast ribbon samples of various thicknesses obtained using monochromatic beam of synchrotron radiation $(\lambda=0.110696 \AA)$.
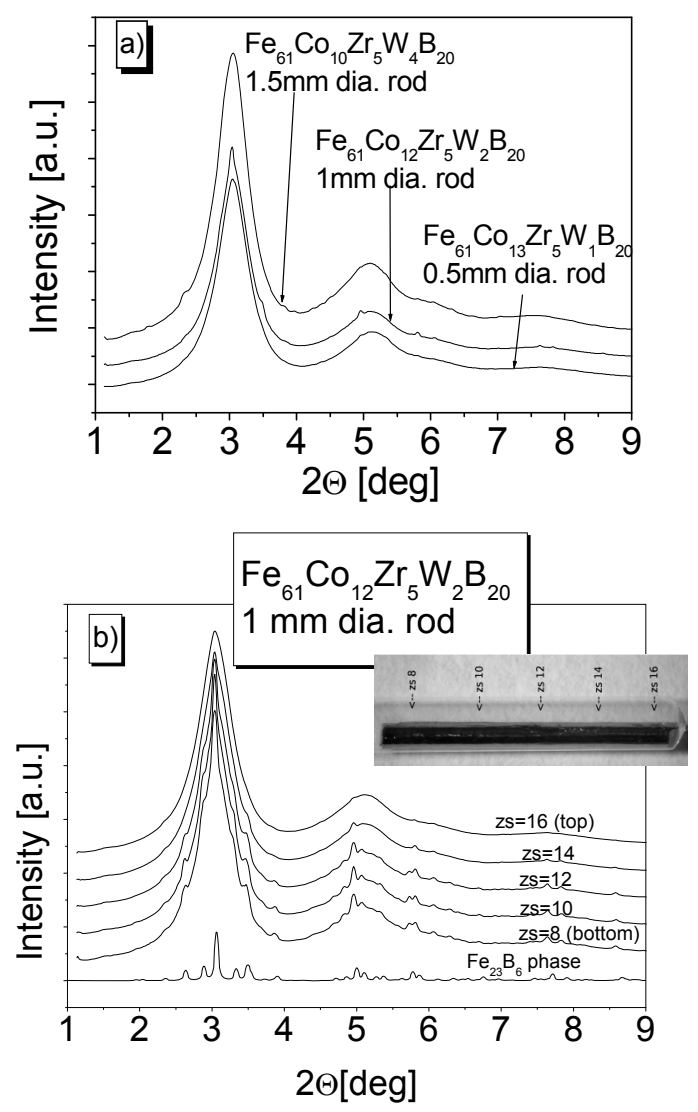

Figure 2 XRD scans for $\mathrm{Fe}_{61} \mathrm{Co}_{10+\mathrm{x}} \mathrm{Zr}_{5} \mathrm{~W}_{4-\mathrm{x}} \mathrm{B}_{20}(\mathrm{x}=0,2,3)$ alloys suction-cast rod samples (a), XRD scans for $1 \mathrm{~mm}$ dia. rod of the $\mathrm{Fe}_{61} \mathrm{Co}_{12} \mathrm{Zr}_{5} \mathrm{~W}_{2} \mathrm{~B}_{20}$ alloy taken along the length of the rod (b), obtained using monochromatic beam of synchrotron radiation $(\lambda=0.110696 \AA)$. 
For the $\mathrm{Fe}_{61} \mathrm{Co}_{10} \mathrm{Zr}_{5} \mathrm{~W}_{4} \mathrm{~B}_{20}$ alloy samples in a form of $1.5 \mathrm{~mm}$ dia. rods, a very low intensity peaks are present on the XRD. This suggests existence of crystalline traces in the sample. Slightly larger peaks were observed for $1 \mathrm{~mm}$ dia. rod of the $\mathrm{Fe}_{61} \mathrm{Co}_{12} \mathrm{Zr}_{5} \mathrm{~W}_{2} \mathrm{~B}_{20}$ alloy. Phase analysis of the sample revealed presence of the metastable $\mathrm{Fe}_{23} \mathrm{~B}_{6}$ crystalline phase that precipitated during rapid solidification. However, a fraction of crystalline phase in this case is minimal comparing to the volume fraction of the amorphous phase.

Decrease of cooling rates with increasing diameter of samples was shown for suction-cast rods and tubes in [10]. Furthermore, changes of cooling rates were demonstrated along the diameter of the samples. Therefore the analysis of changes in the phase constitution of suction-cast samples along their length seems to be an interesting subject, as a presence of such changes would provide evidence of differences in cooling rates along the sample length. The synchrotron X-ray diffraction patterns detected in five points along the length of $1 \mathrm{~mm}$ dia. rod of the $\mathrm{Fe}_{61} \mathrm{Co}_{12} \mathrm{Zr}_{5} \mathrm{~W}_{2} \mathrm{~B}_{20}$ alloy are shown in Fig. 2b. Sectors of the rod close to the top part of copper die during casting are fully amorphous, while areas distant from that point reveal presence of the $\mathrm{Fe}_{23} \mathrm{~B}_{6}$ metastable phase precipitating during rapid solidification. These changes in diffraction patterns prove differences in cooling rates along the rod length.

3.2 Crystallization kinetic and activation energy of crystal growth DSC scans were carried out on amorphous rods of all three alloy compositions, in order to determine the kinetic of crystal growth. The measurements were performed at three different heating rates: 10 , 25 and $40 \mathrm{~K} / \mathrm{min}$ respectively (Fig. 3) and activation energies $\mathrm{E}_{\mathrm{c}}$ were determined using Kissinger equation [3]. Subsequently, relations between $\ln [-\ln (1-\mathrm{x})]$ and $1 / \mathrm{T}$, were determined (Fig.4). In approximation of the linear parts of $\ln [-\ln (1-x)]$ vs. $1 / T$ curves, the $E_{c}$ values obtained from Kissinger plots, were used as references to determine the $\mathrm{m}$ parameters describing dimensions of crystal growth (relation (2)). Furthermore $\mathrm{n}$ parameter was determined from dependences of $\ln [-\ln (1-\mathrm{x})]$ on the $\ln \alpha$ (Fig. 4d). It was shown in Table 1, that the activation energy significantly rise with increasing $\mathrm{W}$ contents. The crystal growth parameters $\mathrm{n}$ and $\mathrm{m}$ are also collected in Table 1. The calculated values of $n$ and $m$ are not integers, which mean that the crystal growth process occurs with different mechanisms and a specific one is predominant for particular alloy. Matusita et al. in [9] have shown that $\mathrm{m}$ parameter is a number of dimensions of crystal growth while heating at constant rate. According to our studies m number seems to be closely related to the glass forming abilities of investigated alloys. The minimum value of $\mathrm{m}$ and the largest value of activation energy were obtained for the $\mathrm{Fe}_{61} \mathrm{Co}_{10} \mathrm{Zr}_{5} \mathrm{~W}_{4} \mathrm{~B}_{20}$ alloy, where the largest diameters of amorphous rods were produced. These suggest a dimensionally limited crystal growth also during rapid solidifica- tion at low cooling rates. Furthermore, a reduction of the activation energy with decrease of $\mathrm{W}$ content was shown. Also the increase of $m$ parameter, from $m=1$ for the $x=0$ alloy to $m=3$ for the $x=3$ alloy sample was observed with decreasing $\mathrm{W}$ content.
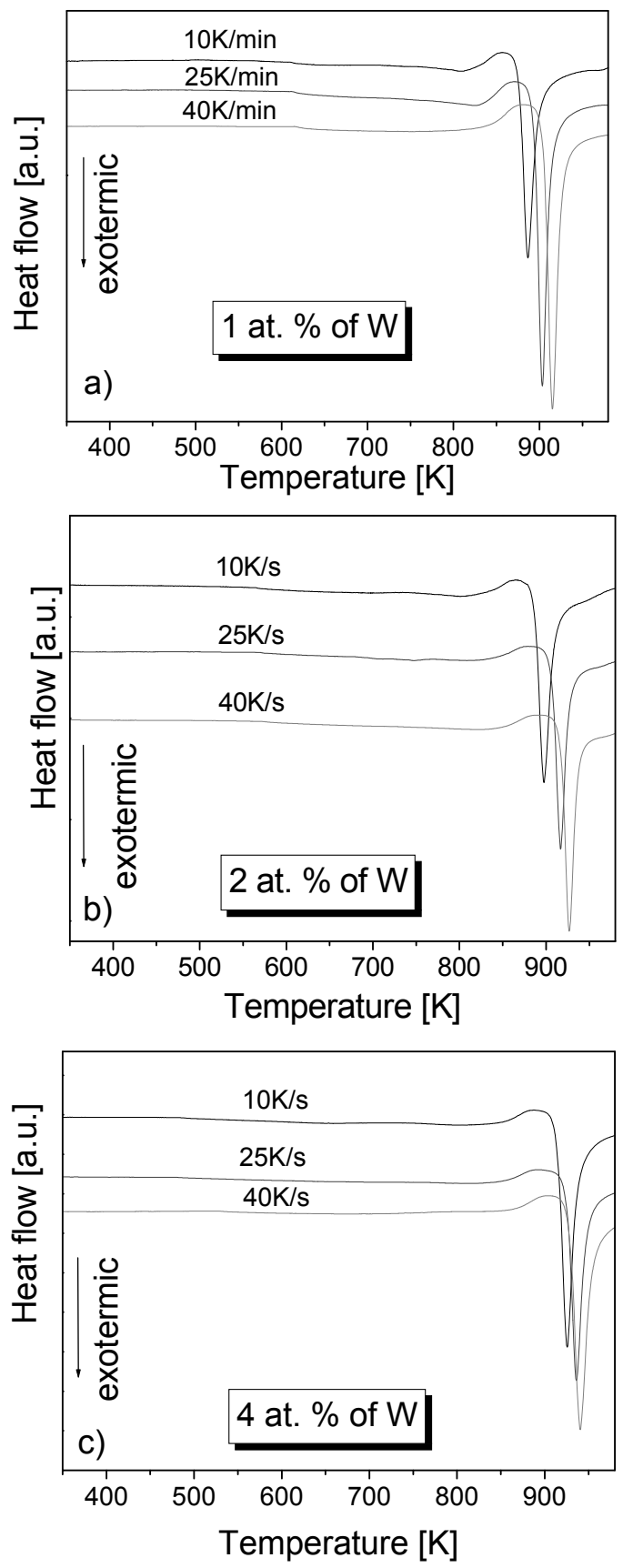

Figure 3 The DSC scans measured at various heating rates for $0.5 \mathrm{~mm}$ diameter (dia.) rod samples of the $\mathrm{Fe}_{61} \mathrm{Co}_{13} \mathrm{Zr}_{5} \mathrm{~W}_{1} \mathrm{~B}_{20}$ alloy (a), $1 \mathrm{~mm}$ dia. rods of $\mathrm{Fe}_{61} \mathrm{Co}_{12} \mathrm{Zr}_{5} \mathrm{~W}_{2} \mathrm{~B}_{20}$ (b) and $\mathrm{Fe}_{61} \mathrm{Co}_{10} \mathrm{Zr}_{5} \mathrm{~W}_{4} \mathrm{~B}_{20}$ (c) alloys. 

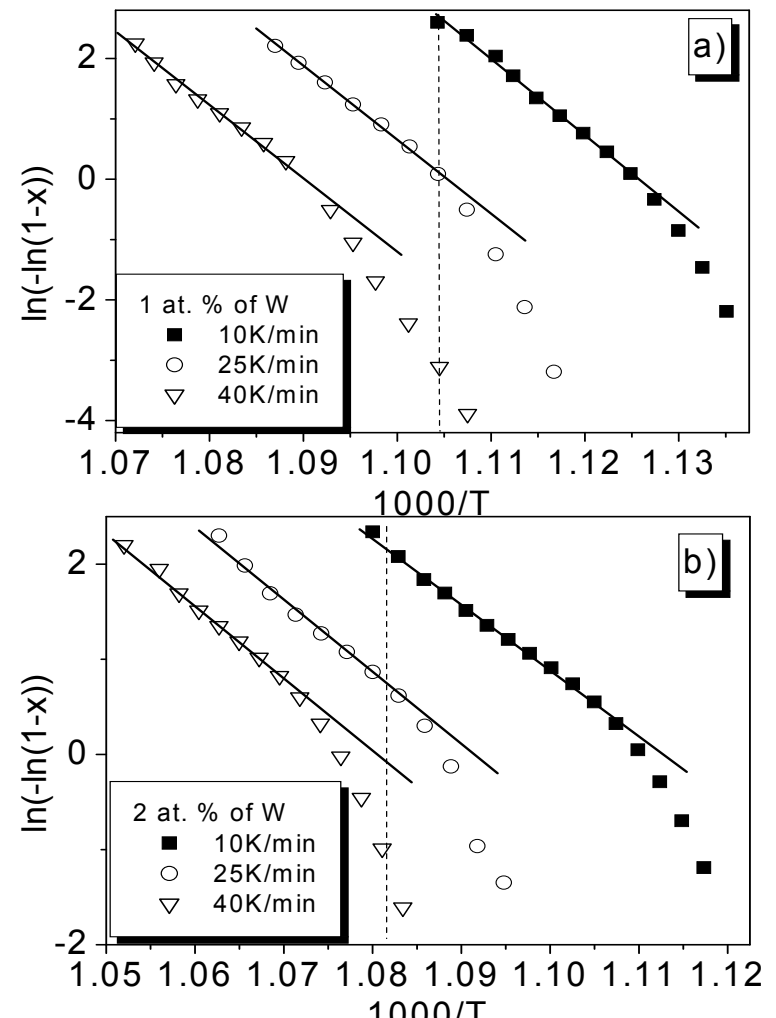
$1000 / T$
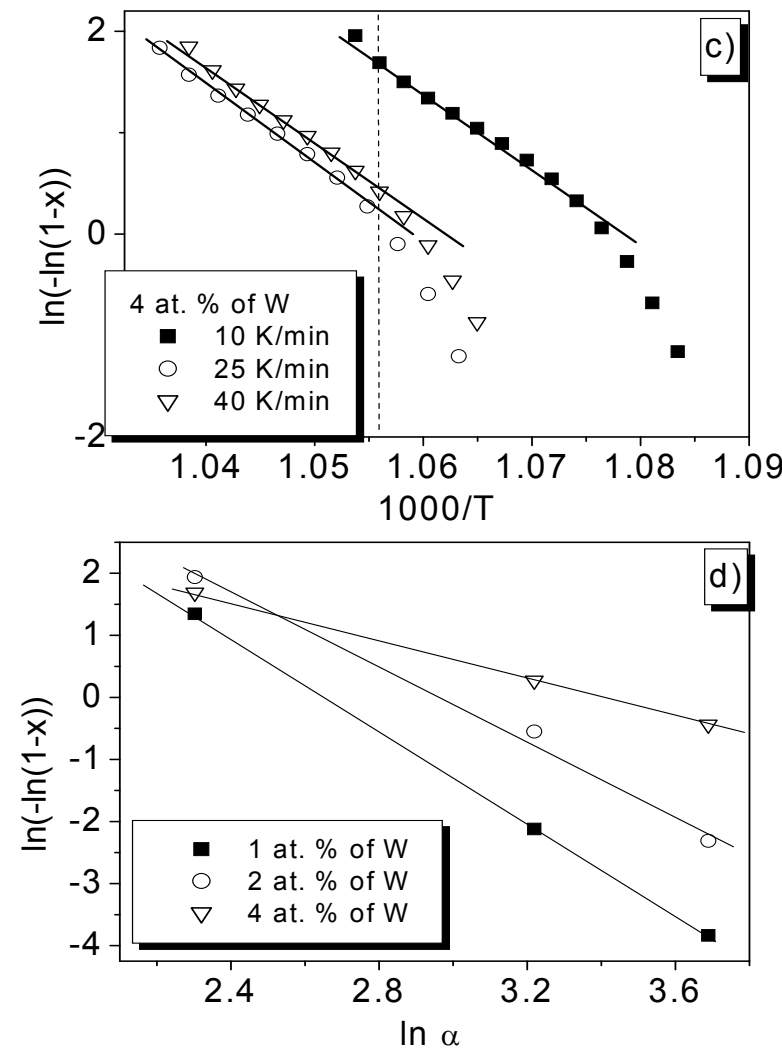

Figure 4 Relations between $\ln (-\ln (1-\mathrm{x}))$ and $1 / \mathrm{T}$ for the $\mathrm{Fe}_{61} \mathrm{Co}_{13} \mathrm{Zr}_{5} \mathrm{~W}_{1} \mathrm{~B}_{20}$ alloy (a), $\mathrm{Fe}_{61} \mathrm{Co}_{12} \mathrm{Zr}_{5} \mathrm{~W}_{2} \mathrm{~B}_{20}$ alloy (b) and $\mathrm{Fe}_{61} \mathrm{Co}_{10} \mathrm{Zr}_{5} \mathrm{~W}_{4} \mathrm{~B}_{20}$ alloy (c); relations between $\ln (-\ln (1-\mathrm{x}))$ and $\ln \alpha$ at constant temperature (d).
For both $\mathrm{x}=2$ and 3 alloys, larger values of $\mathrm{m}$ suggest easier crystal growth during non-isothermal heating. Also for both alloys smaller dimensions of fully glassy samples were obtained.

Table 1 Activation energy $E_{c}$ determined from Kissinger plots $(\mathrm{KP}) ; \mathrm{m}$ and $\mathrm{n}$ parameters as well as $\mathrm{mE}_{\mathrm{c}}$ determined from Matusita model (MM) for $\mathrm{Fe}_{61} \mathrm{Co}_{10+\mathrm{x}} \mathrm{Zr}_{5} \mathrm{~W}_{4^{-}{ }_{\mathrm{x}}} \mathrm{B}_{20}$ alloys (where $\mathrm{x}$ $=0,2,3$ at. $\%$ )

\begin{tabular}{lllll}
\hline $\mathrm{x}$ & $\begin{array}{l}\boldsymbol{m} \boldsymbol{E}_{\boldsymbol{c}} \\
{[\boldsymbol{k J J} / \boldsymbol{m o l}]} \\
(\mathrm{MM})\end{array}$ & $\begin{array}{l}\boldsymbol{E}_{\boldsymbol{c}} \\
{[\boldsymbol{k J} / \boldsymbol{m o l}]}\end{array}$ & $\boldsymbol{m}$ & $\boldsymbol{n}$ \\
\hline 0 & 1020 & 302 & $3.38 \approx 3$ & 3.78 \\
\hline 2 & 650 & 305 & $2.13 \approx 2$ & 2.89 \\
\hline 3 & 623 & 509 & $1.22 \approx 1$ & 1.54 \\
\hline
\end{tabular}

4 Conclusions It was shown that X-ray diffractometry carried out on bulk glassy samples of $\mathrm{Fe}_{61} \mathrm{Co}_{10+\mathrm{x}} \mathrm{Zr}_{5} \mathrm{~W}_{4-\mathrm{x}} \mathrm{B}_{20}(\mathrm{x}=0,2,3)$ alloys, using monochromatic beam of the synchrotron radiation, allows to detect traces of crystalline precipitates formed during rapid solidification of bulk samples. Therefore it is a powerful tool for study the glass forming abilities, as it can give an information from entire volume of bulk samples. Furthermore, synchrotron radiation XRD carried out on $1 \mathrm{~mm}$ dia. rod also shown changes in cooling rates accessible in suctioncasting method along the length of the sample. The studies of crystallization process allowed finding a relation between the glass forming abilities of particular alloy and the activation energy for crystal growth. Furthermore, the studies revealed differences in dimensional crystal growth in alloys of different $\mathrm{W}$ contents.

\section{References}

[1] P. Pawlik, J. All. Compd. 423, 96 (2006).

[2] P. Pawlik, K. Pawlik, H. A. Davies, J. J. Wysłocki, W. Kaszuwara, M. Leonowicz, J. Magn. Magn. Mater. 304, e733 (2006).

[3] H. E. Kissinger, Anal. Chem. 28, 1702 (1957).

[4] T. Ozawa, J. Thermal Anal. 2, 301 (1970).

[5] J. Calmenero, J. M. Barandiaran, J. Non-Cryst. Solids 30, 263 (1979).

[6] J. Colmenero, J. Ilarraz, Thermochem. Acta 35, 381 (1980).

[7] A. Lucci, L. Battizzati, C. Antonione, G. Riontino, J. NonCryst. Solids 44, 287 (1981).

[8] M. E. Fine, Introduction to Phase Transformation in Condensed System (Macmillan, New York, 1964), chap. 3.

[9] K. Matusita, T. Komatsu, R. Yokota, J. Mater. Sci. 19, 291 (1984).

[10] P. Pawlik, K. Pawlik, A. Przybył, Rev. Adv. Mater. Sci. 18, 81 (2008). 